\title{
Management of inferior retinal breaks during pars plana vitrectomy for retinal detachment
}

\author{
V Tanner, M Minihan, T H Williamson
}

\begin{abstract}
Aims-To determine whether it is necessary to support inferior retinal breaks with a scleral explant during pars plana vitrectomy (PPV) for rhegmatogenous retinal detachment (RD).

Methods-A prospective study was carried out on nine eyes of nine consecutive patients undergoing PPV for primary RD with associated inferior retinal breaks and no significant proliferative vitreoretinopathy.

Results-Eight eyes were successfully reattached with a single operation. No cases presented with redetachment because of failed closure of the original inferior breaks.

Conclusions-It is not necessary to support inferior retinal breaks with a scleral explant during PPV for primary RD repair in selected cases.

(BrF Ophthalmol 2001;85:480-482)
\end{abstract}

The use of pars plana vitrectomy (PPV) in the treatment of rhegmatogenous retinal detachment (RD) has gained increasing popularity

Accepted for publication 22 November 2000
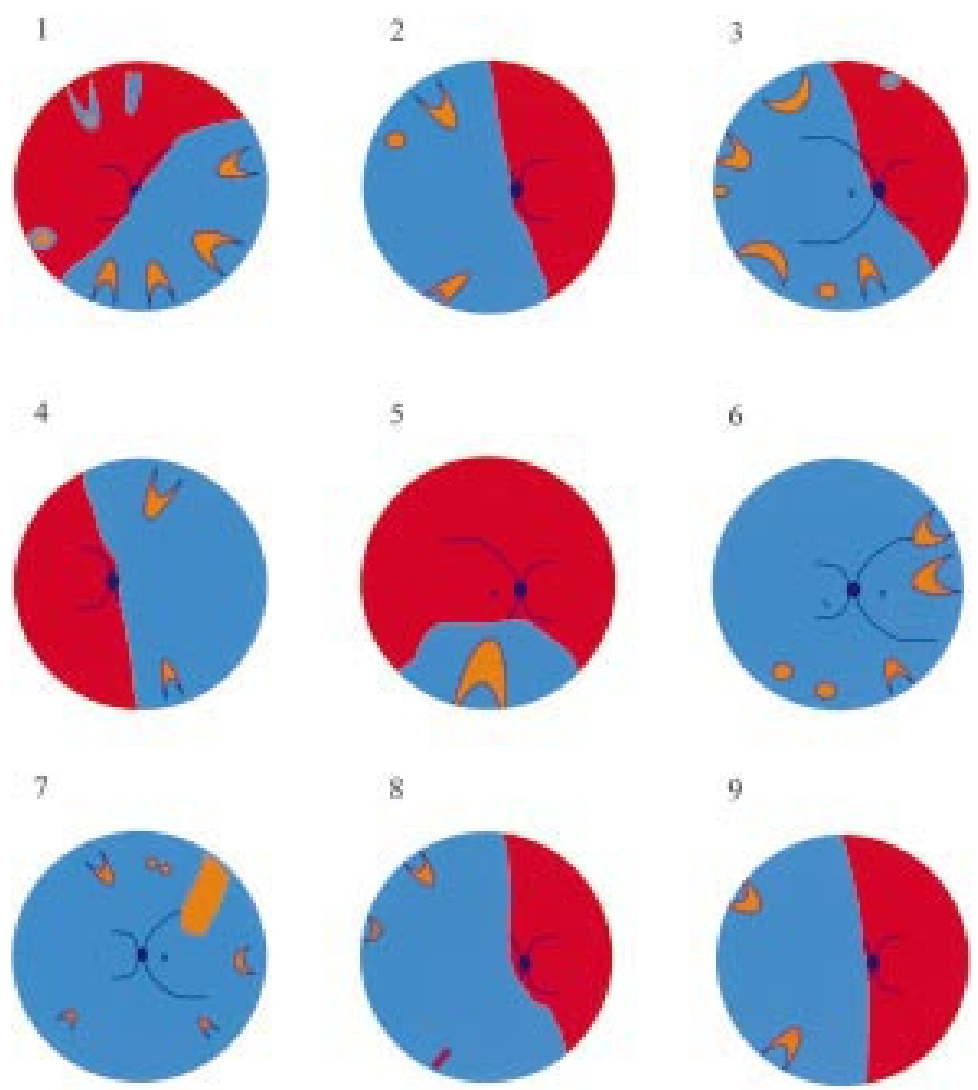

Figure 1 Preoperative diagrams of the retinal detachments and position of associated breaks. over the past 20 years and is often combined with the use of a scleral explant. ${ }^{1-5}$ It is well recognised that the use of scleral explants combined with PPV repair of RD is associated with several risks including hypotony during placement of the buckle with associated choroidal haemorrhage ${ }^{26}$ and longer duration of surgery. ${ }^{4}$ Postoperative complications include refractive change,${ }^{78}$ diplopia, ${ }^{9}{ }^{10}$ explant erosion or infection, ${ }^{911}$ and a risk of decreased retinal blood flow $^{12}$ and anterior segment ischaemia ${ }^{13} 14$

The majority of retinal detachments are associated with superior or midline breaks and where possible we prefer to treat isolated inferior retinal breaks with a conventional scleral buckling procedure. ${ }^{15}$ However, in some cases a PPV is required because of complex retinal breaks which would be awkward to buckle or to provide an improved view allowing more accurate break localisation and treatment. ${ }^{516}$

It is recognised that intraocular tamponade by gas or silicone oil is unable to provide direct support to inferior retinal breaks without vigorous posturing ${ }^{17}$ and it has previously been our practice to use a segmental buckle to support inferior breaks with associated subretinal fluid (SRF) during PPV. ${ }^{2}$ However, this practice is associated with similar risks to use of an encircling element particularly in those patients with high myopia, pathologically thin sclera or scleral inflammation.

We have therefore attempted to determine if scleral explants are required to support inferior retinal breaks following PPV for primary RD in the absence of proliferative vitreoretinopathy (PVR).

\section{Materials and methods}

All patients undergoing PPV to repair acute $\mathrm{RD}$ associated with an inferior retinal break between 4 and 8 o'clock were recruited over a 6 month period. Exclusion criteria included PVR of grade B or greater, ${ }^{18}$ giant retinal tears, and patients judged to be incapable of postoperative posturing. We specifically targeted those patients in whom it had been our previous practice to use an inferior scleral explant in conjunction with PPV and intraocular tamponade.

Patient data are given in Table 1. PPV was chosen as the surgical technique in these cases owing to the large size or number of retinal breaks or to improve the fundal view. Diagrams of the retinal detachments and position of associated breaks are shown in Figure 1.

All patients underwent PPV by one of the authors (VT or THW) using similar techniques. A conventional three port PPV was performed using the Oculus BIOM viewing 
Table 1 Characteristics of patients included in study

\begin{tabular}{|c|c|c|c|c|c|c|c|c|c|}
\hline Case No & Age & Lens status & $\begin{array}{l}\text { Eye } \\
\text { affected }\end{array}$ & $\begin{array}{l}\text { Preop } \\
\text { VA }\end{array}$ & Retinopexy & Tamponade & Posture & $\begin{array}{l}\text { Retinal status } \\
\text { at } 6 \text { months }\end{array}$ & Final VA \\
\hline 1 & 61 & pseudo & $\mathrm{L}$ & $\mathrm{HM}$ & laser & Silicone oil & face down & attached & $6 / 36$ \\
\hline 2 & 49 & phakic & $\mathrm{R}$ & $\mathrm{CF}$ & cryopexy & $12 \% \mathrm{C}_{3} \mathrm{~F}_{8}$ & face down & attached & $6 / 6$ \\
\hline 3 & 62 & pseudo & $\mathrm{R}$ & $6 / 60$ & laser and cryopexy & $12 \% \mathrm{C}_{3} \mathrm{~F}_{8}$ & L side down & attached & $6 / 9$ \\
\hline 4 & 71 & phakic & $\mathrm{L}$ & $\mathrm{HM}$ & cryopexy & $30 \% \mathrm{SF}_{6}$ & $\mathrm{~L}$ side down & attached & $6 / 24$ \\
\hline 5 & 32 & phakic & $\mathrm{R}$ & $6 / 9$ & laser and cryopexy & Silicone oil & face down & attached & $6 / 9$ \\
\hline 6 & 60 & phakic & $\mathrm{R}$ & $\mathrm{CF}$ & cryopexy & $12 \% \mathrm{C}_{3} \mathrm{~F}_{8}$ & face down & attached & $6 / 18$ \\
\hline 7 & 80 & pseudo & $\mathrm{L}$ & $6 / 60$ & laser & $14 \% \mathrm{C}_{3} \mathrm{~F}_{8}$ & face down & attached & $6 / 9$ \\
\hline 8 & 64 & pseudo & $\mathrm{R}$ & $6 / 60$ & cryopexy & $14 \% \mathrm{C}_{3} \mathrm{~F}_{8}$ & L side down & attached & $6 / 9$ \\
\hline 9 & 51 & phakic & $\mathrm{R}$ & $\mathrm{CF}$ & cryopexy & $30 \% \mathrm{SF}_{6}$ & L side down & detached & $6 / 6$ \\
\hline
\end{tabular}

Pseudo = pseudophakic $; \mathrm{VA}=$ visual acuity $; \mathrm{HM}=$ hand movements $; \mathrm{CF}=$ counting fingers .

system (Wetzler, Germany), with removal of accessible vitreous traction from retinal breaks. All breaks were then identified using deep scleral indentation ${ }^{16}$ and treated with transscleral cryopexy or argon endolaser. We did not apply 360 degree prophylactic laser.

In an attempt to ensure maximal and prolonged intraocular tamponade, five cases received $12-14 \% \mathrm{C}_{3} \mathrm{~F}_{8}$ and two cases received $1300 \mathrm{cS}$ silicone oil. Two cases, with relatively less complicated $\mathrm{RD}$, received $30 \% \mathrm{SF}_{6}$ as shown in Table 1. Patients were asked to posture for 10 days, either face down or on one side depending on break position as shown in Figure 1. Posturing was advised for 55 minutes in the hour and no formal posturing aids were used.

Retinal status and visual acuity was assessed at 6 months after initial surgery. In those receiving silicone oil tamponade, silicone oil removal was carried out at 3 months combined with phacoemulsification and lens implant in one patient.

\section{Results}

Outcome measures are illustrated in Table 1. Retinal status refers to the outcome after one operation at 6 months. Overall, 8/9 procedures resulted in a flat retina and an improvement in Snellen visual acuity.

Case 9 detached at 3 weeks after primary vitrectomy following absorption of intraocular gas tamponade. The patient underwent repeat, successful PPV which identified the causative break as a small superonasal horseshoe tear adjacent to the scleral entry site. No other patients developed significant complications.

\section{Discussion}

In this pilot study we have addressed whether scleral buckling is required to ensure successful retinal reattachment following PPV in patients with inferior retinal breaks. Our overall success rate of reattachment of the retina with one procedure in this study was $8 / 9(89 \%)$. This is consistent with that reported in other series evaluating primary $\mathrm{RD}$ repair in the $\mathrm{UK}^{119} 20$ and with studies of primary PPV in RD repair. ${ }^{25521}$ One of the inherent problems in the use of PPV is the difficulty of producing a direct tamponade on inferior retinal breaks using currently available intraocular tamponade agents. ${ }^{17} 22$ Perfluorocarbon liquids have been used on a short term basis for postoperative tamponade of inferior breaks but are associated with retinal toxicity, ${ }^{23}$ an increased risk of $\mathrm{PVR}^{24}$ and require further intervention to ensure removal from the eye. ${ }^{25}$
Although several authors have addressed the issue of PPV for RD few have specifically investigated the management of inferior retinal breaks and the use of supplementary scleral buckles. Gartry et al identified eight eyes with primary $\mathrm{RD}$ associated with inferior retinal breaks in a mixed series of 114 eyes undergoing PPV. They treated these cases with a supplementary inferior segmental buckle and achieved $75 \%(6 / 8)$ success with one operation.

Heimann $e t a l^{26}$ in a retrospective series of 53 patients identified six patients with primary $\mathrm{RD}$ associated with inferior retinal breaks which they treated with PPV and $\mathrm{SF}_{6}$ tamponade without scleral buckle. Retinal redetachment occurred in $50 \%(3 / 6)$ of these eyes but no information is provided on the exact cause of redetachment in this group. Campo et $a l^{7}$ reported on 283 consecutive pseudophakic eyes undergoing PPV without the use of scleral buckling to repair RD. They reported an $88 \%$ reattachment rate with one operation that included gas tamponade and 360 degree prophylactic laser. No information was provided on the position of retinal breaks. Escoffery et $a l^{28}$ identified two cases with inferior breaks out of a mixed series of 29 eyes with RD treated with PPV but no scleral buckle. However, no information is given on the exact characteristics of these breaks and on anatomical outcome in these cases.

The introduction of wide angle viewing systems, such as the BIOM, now make it easier to maximise removal of vitreous gel and relieve vitreous traction from retinal breaks during PPV. The reduction in risk of subsequent vitreoretinal traction may make scleral buckling redundant in these selected cases. We would not recommend the avoidance of inferior scleral buckling in all patients with inferior breaks, particularly in those patients who are unable to posture, without further larger studies. However, in this small series we have demonstrated that scleral buckling is not always necessary to achieve retinal reattachment in PPV repair of $\mathrm{RD}$ due to inferior breaks in the absence of PVR.

1 Ah-Fat FG, Sharma MC, Majid MA, et al. Trends in vitreoretinal surgery at a tertiary referral centre: 1987 to 1996 . Br f Ophthalmol 1999;83:396-8.

2 Gartry DS, Chignell AH, Franks WA, et al. Pars plana vitrectomy for the treatment of rhegmatogenous retinal detachment uncomplicated by advanced proliferative vitreoretinopathy. Br f Ophthalmol 1993;77:199-203.

3 Leaver P. Expanding the role of vitrectomy in retinal Leaver P. Expanding the role of vitrectomy in retinal
reattachment surgery. (Editorial) Br f Ophthalmol 1993;77: 197. 
4 Hakin KN, Lavin MJ, Leaver PK. Primary vitrectomy for rhegmatogenous retinal detachment. Graefes Arch Clin Exp rhegmatogenous retinal deta

5 Wong D, Billington BM, Chignell AH. Pars plana vitrectomy for retinal detachment with unseen retinal holes. Graefes Arch Clin Exp Ophthalmol 1987;225:269-71.

6 Tabandeh H, Sullivan PM, Smahliuk P, et al. Suprachoroidal hemorrhage during pars plana vitrectomy. Risk factors and "outcomes". Ophthalmology 1999;106:236-42.

7 Rubin ML. The induction of refractive errors by retinal detachment surgery. Trans Am Ophthalmol Soc 1976;73: 452-90.

8 Goel R, Crewdson J, Chignell AH. Astigmatism following retinal detachment surgery. Br f Ophthalmol 1983;67:3279.

9 Arruga A. Motility disturbances induced by operations for retinal detachment. Mod Probl Ophthalmol 1977;18:408reting

10 Fison PN, Chignell AH. Diplopia after retinal detachment surgery. Br F Ophthalmol 1987;71:521-5.

11 Flindall RJ, Norton EW, Curtin VT, et al. Reduction of extrusion and infection following episcleral silicone implants and cryopexy in retinal detachment surgery. $A m \mathcal{F}$

12 Yoshida A, Feke GT, Green GJ, et al. Retinal circulatory changes after scleral buckling procedures. Am $\mathcal{F}$ Ophthalmol 1983;95:182-8.

13 Ryan SJ, Goldberg MF. Anterior segment ischemia following scleral buckling in sickle cell hemoglobinopathy. Am f Ophthalmol 1971;72:35-50.

14 Kwartz J, Charles S, McCormack P, et al. Anterior segment ischaemia following segmental scleral buckling. $\mathrm{Br} f$ Ophthalmol 1994;78:409-10.

15 Woon HC, Burdon MA, Chignell AH. Comparison of pars plana vitrectomy and scleral buckling for uncomplicated rhegmatogenous retinal detachment. Curr Opin Ophthalmol 1995;6:76-9.

16 Rosen PH, Wong HC, McLeod D. Indentation microsurgery: internal searching for retinal breaks. Eye 1989;3:277-81.
17 Fawcett IM, Williams RL, Wong D. Contact angles of substances used for internal tamponade in retinal detachment surgery. Graefes Arch Clin Exp Ophthalmol 1994;232:438surg.

18 Machemer R, Aarberg TM, Freeman HM, et al. An updated lassification of retinal detachment with proliferative vitreoretinopathy. Am f Ophthalmol 1991;112:159-65.

19 Sullivan PM, Luff AJ, Aylward GW. Results of primary retinal reattachment surgery: a prospective audit. Eye 1997;11: $869-71$

20 Snead MP, Scott JD. Results of primary retinal detachment surgery: a prospective audit. Letter. Eye 1998;12:750-1.

21 Bartz-Schmidt KU, Kirchhof B, Heimann K. Primary vitrectomy for pseudophakic retinal detachment. $\mathrm{Br} \mathcal{F} \mathrm{Oph}$ thalmol 1996;80:346-9.

22 Williams R, Wong D. The influence of explants on the physical efficiency of tamponade agents. Graefes Arch Clin Exp Ophthalmol 1999;237:870-4.

23 Orzalesi N, Migliavacca L, Bottoni F, et al. Experimental short-term tolerance to perfluorodecalin in the rabbit eye: a histopathological study. Curr Eye Res 1998;17:828-35.

24 De Molfetta V, Bottoni F, Arpa P, et al. The effect of simultaneous internal tamponade on fluid compartmentalization and its relationship to cell proliferation. Retina 1992;12: S40-5

25 Bottoni F, Sborgia M, Arpa P, et al. Perfluorocarbon liquids as postoperative short-term vitreous substitutes in complicated retinal detachment. Graefes Arch Clin Exp Ophthalmol 1993;231:619-28

26 Heimann H, Bornfeld N, Friedrichs W, et al. Primary vitrectomy without scleral buckling for rhegmatogenous retinal detachment. Graefes Arch Clin Exp Ophthalmol $1996 ; 234: 561-8$

27 Campo RV, Sipperley JO, Sneed SR, et al. Pars plana vitrectomy without scleral buckle for pseudophakic retinal detachments. Ophthalmology 1999;106:1811-15.

28 Escoffery RF, Olk RJ, Grand MG, et al. Vitrectomy without scleral buckling for primary rhegmatogenous retinal detachment. Am f Ophthalmol 1985;99:275-81. 